\title{
Da raça à doença em Casa-grande e senzala
}

\section{From race to bealth in Master and slave}

Luiz Antonio Teixeira

Pesquisador da Casa de Oswaldo Cruz/Fiocruz Av. Brasil, 4365

21040-360 Rio de Janeiro - RJ Brasil

e-mail: teixeira@omega.lncc.br

TEIXEIRA, L. A.: 'Da raça à doença em Casagrande e senzala'.

História, Ciências, Saúde-Manguinhos, IV(2):231-243 jul.-out. 1997.

$\mathrm{O}$ artigo analisa como Gilberto Freyre trata das questões de saúde na obra Casa-grande e senzala: formação da família brasileira sob o regime de economia matriarcal. A análise volta-se inicialmente para a influência do movimento pelo saneamento dos sertões, surgido no final da década de 1910. Em seguida, observa a relação que o autor atribui ao problema da sífilis no Brasil, procurando compreender a relação dessa valorização com as questões de raça e miscigenação sempre presentes em sua obra. Por fim, procura situar as idéias de Freyre no ideário eugênico em voga no Brasil, período de elaboração de sua obra.

PALAVRAS-CHAVE: Gilberto Freyre, raça, saúde, história.

TEIXEIRA, L. A.: 'From Race to Health in Master and slave'.

História, Ciências, Saúde-Manguinhos, IV (2):231-243, Jul.-Oct. 1997.

The article analyzes how Gilberto Freyre addresses health-related issues in his book Master and slave. The first point of focus is how the sanitation movement that emerged in the sertão region in the late 1910 s influenced Freyre's essay. The article next endeavors to understand the relation between Freyre's emphasis on the problem of syphilis in Brazil and the issues of race and miscegenation, both of which are constants in his works. Lastly, the article endeavors to situate Freyre's ideas with in the ideological framework of engenics that was in fashion in Brazil at the time his works were written.

KEYWORDS: Gilberto Freyre, race, health, history. 
${ }^{1}$ Freyre (1933, xlvii).

\footnotetext{
2 O Instituto Oswaldo Cruz, centro de pesquisa, ensino e produção de imunizantes, criado em 1900 no Rio de Janeiro, teve papel destacado no processo de revelação das condições de vida no interior do país. Entre 1912 e 1917, várias expedições científicas organizadas por esta instituição cingiram o interior do país, elaborando um comovente retrato das questões de saúde de nossa população. Os relatórios dessas expedições, além de trazer a público os problemas sociais do interior, faziam um amplo inventário da multiplicidade de enfermidades que assolavam nossos sertanejos. Sobre o papel das expedições científicas na redescoberta do interior do país, ver Skidmore (1976) e Benchimol (1990).
}

C asa-grande e senzala é um marco do pensamento social brasileiro. Primorosa obra de interpretação do Brasil, põe em relevo o processo de miscigenação em nossa sociedade, apontando para a importância das contribuições das diversas raças em nossa formação. Publicado em 1933, este ensaio traz a marca das discussões sobre saúde havidas a partir do final da década de 1910.

Vi uma vez, depois de quase três anos de ausência do Brasil, um bando de marinheiros nacionais - mulatos e cafuzos - descendo não me lembro se do São Paulo ou do Minas pela neve mole do Brooklyn. Deram-me a impressão de caricaturas de homens. E veio-me à lembrança a frase de um livro de viajante americano que acabara de ler sobre o Brasil, 'the fearfuly mongrel aspect of population'. A miscigenação resultava naquilo. Faltou-me quem me dissesse então, como em 1929 Roquette-Pinto aos arianistas do Congresso Brasileiro de Eugenia, que não eram simplesmente mulatos ou cafuzos os indivíduos que eu julgava representarem o Brasil, mas cafuzos e mulatos doentes. ${ }^{1}$

Esta passagem, do prefácio à primeira edição de Casa-grande e senzala, já aponta a relevância da temática da saúde no trabalho. Mais do que isso, anuncia que as questões de saúde e doença muitas vezes estão relacionadas às de raça, possibilitando uma multiplicidade de interpretações sobre o papel de cada uma em nosso desenvolvimento histórico.

É justamente o binômio raça-doença que iremos discutir, observando como Freyre trabalha a questão em sua obra. Pretendemos relacionar a peculiaridade de apresentação dessa temática com a relevância que as questões de saúde tiveram a partir do final da década de 1910. Nos deteremos, com mais detalhes, nas observações de Freyre sobre o problema da sífilis no Brasil, o que se justifica pelo fato desta doença ter sido identificada por muitos médicos e intelectuais como um grave fator de degeneração da raça, fruto do processo de miscigenação ocorrido no país.

\section{A saúde como questão}

A década de 1910 marca o período em que a saúde de nossa população passa a ser vista como um problema importante por grande parte da intelectualidade brasileira. No início do século, Euclides da Cunha (1902) havia alertado para o fato de que o interior do país abrigava uma massa de fortes mestiços resistentes às intempéries dos sertões. Mas foi a partir da publicação dos relatórios de expedições científicas, que se embrenharam pelo interior do país, que a intelectualidade dos centros urbanos tomou consciência de que a cruel realidade de vida do interior não era sobrepujada pela força do sertanejo. Pelo contrário, ela restringia nossa capacidade econômica e nos condenava à eterna inferioridade frente as nações desenvolvidas. ${ }^{2}$ 
3 Sobre a reforma sanitária na década de 1920, ver Labra (1985)

e Benchimol e

Teixeira (1993).
Em 1916, Miguel Pereira, médico e professor da Faculdade de Medicina do Rio de Janeiro, pronunciaria, em discurso, que "o Brasil é um grande hospital". Num contexto de exacerbação do nacionalismo deflagrado pela guerra na Europa, de agudização das críticas à experiência republicana e de desenvolvimento da medicina experimental, apontando para a possibilidade de profilaxia e cura de diversas doenças, a frase-denúncia se tornaria símbolo e lema de combate de grande parte da nossa intelectualidade pelo saneamento dos sertões do país. Esses anseios se unificaram em 1918 com a criação da Liga Pró-Saneamento do Brasil, entidade civil dirigida por Belisário Penna, sanitarista e cientista do Instituto Oswaldo Cruz (IOC).

Objetivando recuperar o país 'doente' e integrar à sua porção civilizada os homens do interior, a Liga Pró-Saneamento deflagrou intensa campanha pelo saneamento rural. A partir de sua criação, aglutinou diversos setores da nossa elite política e intelectual. De pronto, associaram-se a ela vários membros da Academia Nacional de Medicina, professores da Faculdade de Medicina do Rio de Janeiro, cientistas do IOC, antropólogos do Museu Nacional, militares, educadores, juristas e o próprio presidente da República, Wenceslau Brás (Lima e Hochman, 1996, p. 26).

Numa visão retrospectiva, podemos afirmar a importância da mobilização pelo saneamento e, em particular, da campanha empreendida pela liga, por suas conseqüências políticas e institucionais. Destacam-se entre elas a criação, em 1918, do Serviço de Saneamento Rural, que objetivava o controle de doenças endêmicas nas zonas rurais; do Serviço de Medicamentos Oficiais, que produzia quinina para o controle da malária; e do Departamento Nacional de Saúde Pública, agência federal que passou a centralizar as ações de saúde pública no país a partir de 1919. ${ }^{3}$

Mas as conseqüências desse processo extrapolam o plano institucional, também se verificando ao nível das idéias. Além da conscientização de nossas elites em relação à necessidade de transformação da realidade vivida no meio rural, a discussão em torno da saúde teve um saldo significativo e duradouro para o pensamento social brasileiro. Segundo Hochman (op. cit., p. 37),

O movimento pelo saneamento do Brasil teve conseqüências de longo prazo em termos de políticas públicas e identidades profissionais, e seus diagnósticos e argumentos ajudaram a legitimar a presença do Estado no campo da saúde pública. E, o mais significativo, a descoberta da importância sociológica da doença foi incorporada por parte considerável daqueles que refletiram sobre o Brasil e sobre a identidade de ser brasileiro.

Incorporação esta que assumiu caráter bastante peculiar, mostrando-se como um elemento central na mudança de eixo do já antigo debate em torno do determinismo racial como impeditivo 
${ }^{4}$ Referimo-nos ao artigo 'Velha praga', publicado em 1914 em O Estado de S. Paulo. Em 1918, este artigo foi reunido a outros $\mathrm{e}$ editado com o título de Urupez. Neste mesmo ano, Lobato publicou o livro $M r$. Lang e o Brasil e problema vital, onde retornava a questão do caboclo com uma visão medicalizada

5 Não nos deteremos nesse ponto por acreditar que esta visão fazia parte do ambiente cultural da época, a que poucos autores escapavam. do nosso desenvolvimento. A idéia da doença como elemento de enfraquecimento de nossa população retirava do determinismo racial muito de seu poder de persuasão.

Monteiro Lobato é o melhor exemplo dessa incorporação da doença ao pensamento social. O contato com os sanitaristas da liga, em especial com Belisário Penna, operou uma verdadeira conversão nesse escritor. Seu Jeca Tatu, apresentado ao mundo, em 1914, como uma praga nacional, um parasita inadaptável à civilização, foi alçado, em 1918, à posição de vítima das péssimas condições de saúde dos nossos sertões. Ele não era assim, estava assim. ${ }^{4}$

Gilberto Freyre também seria influenciado por esta nova forma de encarar as questões de saúde e doença. Embora sua análise não apresente o tom de denúncia de Monteiro Lobato, sua obra incorpora sistematicamente as questões de saúde, que são centrais em suas explicações sobre o processo de constituição de nossa sociedade.

\section{Raça e doença}

O parágrafo que serve de epígrafe a esse texto já aponta que a questão da miscigenação e suas conseqüências são centrais em Casa-grande e senzala. Mostra, também, que o autor não se filia às correntes de pensamento que acreditavam que o processo de miscigenação havido no Brasil fosse determinante de uma pretensa inferioridade racial de nosso povo. ${ }^{5}$ Tomando por base os estudos da antropologia cultural, em especial de seu mestre em Columbia, o antropólogo Franz Boas, Freyre (1933, p. xlviii) salienta que "aprendeu a considerar fundamental a diferença entre raça e cultura; a discriminar entre os efeitos de relações puramente genéticas e os de influências sociais, de herança cultural e de meio", e arremata afirmando que todo o seu trabalho se assenta nesse critério de diferenciação.

Essa postulação é o gancho utilizado pelo autor para começar a apresentar o quadro físico, político e sócio-econômico que delineia o cenário de formação da nossa sociedade. A monocultura latifundiária e o sistema escravista passam, então, a ser analisados sistematicamente. Seus efeitos, tanto no plano material como no plano das idéias, serão vistos como os verdadeiros condicionantes de várias características do nosso povo muitas vezes atribuídas à raça. Logo, a questão da saúde de nossa população vai emergir da análise. De início, relacionada ao clima e às condições de nutrição.

Embora Freyre procure se afastar das concepções de determinismo climático, ele reitera a noção de que o clima exerce influência na formação e no desenvolvimento das sociedades. Se não diretamente, pelo menos no condicionamento de aspectos econômicos e culturais. Além disso, aceita que as condições climá- 
ticas dos países quentes predispõem seus habitantes a doenças desconhecidas ou inexistentes nos países frios e lhes obscurece a força de trabalho. No entanto, ele procura relativizar essa idéia acrescentando que, no terreno dos agravos para a saúde, embora as estatísticas mostrem que certas doenças e alterações de comportamento possam se ligar aos climas quentes, é necessário não exagerar essa relação sem levar em conta causas sociais e econômicas - como a doença, a pobreza, a má alimentação etc. que se ligam geralmente às condições de clima (idem, pp. 13-4).

Para Freyre, a influência do clima na organização social vai diminuindo em proporção direta ao desenvolvimento das técnicas que permitem a modificação de seus efeitos sobre o homem e o meio. Nesse sentido, cada vez mais, o clima deixa de ser um obstáculo ao pleno desenvolvimento das sociedades. No entanto, permanece como um elemento de grande importância na interpretação retrospectiva da nossa sociedade, uma vez que, no período da colonização, as agruras do clima se mostraram muito mais presentes para os portugueses, determinando sua forma de morar, vestir e se alimentar.

É justamente a questão da alimentação que mais chama atenção ao autor. Freyre (idem, p. li) observa que vários males atribuídos à miscigenação, como a incapacidade para o trabalho, a saúde instável, a apatia e as perturbações do crescimento, são, na verdade, subprodutos da monocultura latifundiária, engendrados pelo mau suprimento de víveres, inadequados, e, muitas vezes, de qualidade imprópria, o que determinava a subnutrição de grande parte da população.

A importância da hiponutrição ... traz a problemas indistintamente chamados de "decadência" ou "inferioridade" de raças, novos aspectos e, graças a Deus, maiores possibilidades de solução. Salientam-se entre as conseqüências da hiponutrição a diminuição da estatura, do peso e do perímetro torácico; deformações esqueléticas; descalcificação dos dentes; insuficiências tiróidea, hipofisária e gonadial provocadoras da velhice prematura, fertilidade em geral pobre, apatia, não raro infecundidade. Exatamente os traços de vida estéril e de físico inferior que geralmente se associam às sub-raças; ao sangue maldito das chamadas "raças inferiores".

Segundo o autor, o latifúndio escravocrata determinou a homogeneização da produção de subsistência fazendo com que se consumisse de Norte a Sul do país o mesmo tipo de alimentação, baseada em farinha de mandioca e milho, conservando-se como especialidades regionais somente as verduras e frutas. Além disso, o completo desinteresse dos senhores de terras pela produção de gêneros para o consumo interno relegou à instabilidade a produção de víveres efetuada somente por colonos. Como resultado, grande 
${ }^{6}$ Freyre assinala que 0 planalto paulista pode ter sido a única região escravocrata que não tenha tido esse perfil alimentar, em virtude do pouco sucesso da cultura da cana nos primeiros séculos da colonização ter levado à apolicultura. parte da população conviveria com deficiências protéicas advindas da falta de carne fresca, leite, ovos, legumes. ${ }^{6}$

Mas, segundo Freyre, a subnutrição não agia homogeneamente no processo de degeneração do elemento nacional. A precariedade da agricultura de subsistência fez com que os brancos das casasgrandes e os negros das senzalas fossem os grupos mais bem alimentados do período escravista, estando toda a camada de homens livres em pior situação de nutrição. Isso determinaria que os negros e os brancos tivessem como descendentes elementos mais fortes e sadios e que da população média, livre e mestiça descendessem os mais débeis e incapazes. Nesse ponto, a análise de Freyre encontrará a argumentação que deu base à campanha pelo saneamento observada na primeira seção. A má alimentação, o crônico estado de fraqueza desses homens livres, tornava-os presa fácil da multiplicidade de doenças que assolavam as zonas interioranas. Não se tratava de um problema advindo da miscigenação. Absolvidos pela raça, nossos caboclos estavam condenados à inferioridade e à improdutividade pelas mais diversas manifestações patológicas causadas por uma histórica insuficiência alimentar.

Quando toda essa quase inútil população de caboclos e brancarões, mais valiosa como material clínico do que como força econômica, se apresenta no estado de miséria física e de inércia produtiva em que a surpreenderam Miguel Pereira e Belisário Penna, os que lamentam não sermos puros de raça nem o Brasil região de clima temperado o que logo descobrem naquela miséria e naquela inércia é o resultado dos coitos para sempre danados, de brancos com pretas, de portugueses com índias. É da raça a inércia ou a indolência. ...

Do que pouco ou nenhum caso tem feito essa sociologia, ... mais preocupada com os efeitos do clima do que com os de causas sociais suscetíveis de controle ou retificação, e da influência que sobre as populações mestiças, principalmente as livres, terão exercido não só a escassez de alimentação devida à monocultura e ao regime de trabalho escravo...

Não temos dúvidas de que Freyre foi influenciado pelos sanitaristas das décadas de 1910 e 1920. Ao relacionar a questões de saúde muitos dos males antes atribuídos à raça e ao meio, e afirmar a possibilidade de transformação do quadro de indigência de grande parte de nossa população, ele retoma os principais argumentos do movimento pelo saneamento.

Não é sem razão que, no já comentado parágrafo que nos serviu de epígrafe, Freyre recorre a Roquette-Pinto para admitir que as "caricaturas de homens" que vira descendo do navio eram cafuzos e mulatos doentes. No I Congresso Brasileiro de Eugenia, realizado no Rio de Janeiro em 1929, o então diretor do Museu Nacional e membro da Liga Pró-Saneamento afirmava que a existência de um 
grande número de indivíduos somaticamente deficientes em várias regiões do país não se devia a questões de ordem racial, mas a causas patológicas passíveis de serem suprimidas por ações de política sanitária e educativa. A seu ver, não se tratava de um problema de antropologia, mas de saúde pública (Roquette-Pinto, 1929).

\section{Herança racial ou problema social: a sífilis e seu legado}

Já foi mostrado como Freyre procura desarmar alguns argumentos racistas das análises sociais, mostrando que muitos problemas atribuídos à raça estão imbricados com questões de ordem sócioeconômica e cultural. Assim, a fraqueza e improdutividade dos nossos caboclos são vinculadas aos problemas de sua alimentação e, de maneira bastante genérica, aos diversos agravos nas condições de saúde daí derivados. Nesse quadro, as verminoses, a malária, a anemia, o beribéri são vistos, em poucas linhas, como os principais males que atuam sobre a nossa população mestiça. Somente a sífilis ocupa posição de relevo entre os problemas de saúde observados em Casa-grande e senzala. Esta preocupação tem como base o fato de que a sífilis foi identificada com problemas que transcendiam a saúde individual, transbordando para questões relacionadas à família, à raça e à nação. Por isso, ao tratar dessa doença, nosso autor apresenta novas preocupações. Não se trata apenas de atribuir o mal à subnutrição. Freyre objetiva, agora, mostrar que a doença não é autóctone e absolver o elemento nacional, em especial o negro, da culpa pela sua larga disseminação em nossa sociedade.

Segundo Carrara (1995), a reflexão médica sobre a sífilis, a partir da década de 1920, teve grande impacto sobre o pensamento social brasileiro. Desde o final do século XIX, a crença na hereditariedade dessa doença e no seu alto nível de incidência fez com que ela fosse vista como importante fator de degeneração da raça, conseqüência negativa da miscigenação de nosso povo. A partir da década de 1920, a observação médica sobre a sífilis se empenha em separar a doença da miscigenação, atribuindo-lhe o caráter de patologia social.

Acreditamos que esse redimensionamento do problema da sífilis frente ao da miscigenação não se deu de forma isolada. Ele foi fruto do processo de incorporação das questões de saúde por nossas elites intelectuais e políticas. Também se relacionou a outros fatores, como o fortalecimento do nacionalismo, como mostra Carrara (idem, p. 141) quando se remete à origem da doença entre os brasileiros:

Efetivamente parece que os sifilógrafos contribuíram de modo significativo para a consolidação, durante os anos 20 , de um 
${ }^{7}$ Até hoje se desconhece a origem do mal sifilítico. É sabido que, antes da era dos descobrimentos, a doenca era desconhecida na Europa, mas não se conhece a região onde se originou. A afirmação de Freyre de que a sífilis não era uma doença brasileira, assim como grande parte de suas reflexões sobre a doença, se apóia nos trabalhos de Oscar da Silva Araújo, filho do sifilógrafo Silva Araújo e grande especialista na história da sífilis no Brasil. pensamento social, com forte apelo nacionalista, que procurou valorizar o Brasil também pelo que possuía de não europeu, deixando de atribuir as razões de todos os nossos males exclusivamente às heranças ameríndia e africana. Assim, no mesmo momento em que, em seu famoso Retrato do Brasil, Paulo Prado escrevia que dos portugueses havíamos herdado a melancolia, a cobiça e a luxúria, nossos sifilógrafos acrescentavam: e a sífilis..."

É justamente a questão do surgimento da sífilis em nosso país um dos aspectos mais discutidos por Freyre. A seu ver, a doença chegou ao Brasil junto com os primeiros europeus. ${ }^{7}$ Não com a grande leva de portugueses que aqui viriam edificar a sociedade colonial, mas com os primeiros aventureiros que só deixaram em nossa terra a mancha da sífilis e da miscigenação.

A sifilização do Brasil resultou, ao que parece, dos primeiros encontros, alguns fortuitos, de praia, de europeus com índias, não só de portugueses como de franceses e espanhóis. Mas principalmente de portugueses e franceses. Degredados, cristãos-novos, traficantes normandos de madeira de tinta que aqui ficavam, deixados pelos seus para irem se acamaradando com os indígenas; e que acabavam, muitas vezes, tomando gosto pela vida desregrada no meio de mulher fácil e à sombra de cajueiros e araçazeiros (Freyre, 1933, p. 49).

Em relação à origem da doença, ele comunga com a posição da maioria dos médicos de sua época. Segundo Carrara (1995), em virtude do estigma atribuído à doença, todos os povos procuraram imputar sua origem a terceiros, mas foi entre as duas primeiras décadas deste século que a hipótese de a sífilis ser uma doença estrangeira se firmou entre os médicos brasileiros. Embora se acreditasse na origem americana do mal, pensava-se que ele deveria ter vindo das Antilhas.

No que diz respeito à contaminação de nossos índios e, posteriormente, do elemento escravo, Freyre (1933, p. 47) procura mostrar que ela se iniciou nos primeiros contatos com os povoadores, na fase de exploração costeira que antecedeu a verdadeira empresa colonial. O início da miscigenação marcaria também o início da sifilização. Mas ele adverte que esses dois acontecimentos não se identificam. O primeiro traria a marca distintiva do povo brasileiro na sua positividade; o segundo legaria aos nossos a depauperação física e a deformação plástica.

A vantagem da miscigenação correspondeu no Brasil à desvantagem tremenda da sifilização. Começaram juntas, uma a formar o brasileiro - talvez o tipo ideal do homem moderno para os trópicos, europeu com sangue negro ou índio a avivar-lhe a energia; outra a deformá-lo. Daí certa confusão de responsabilidades; atribuindo muitos à miscigenação o que tem sido obra principalmente da sifilização; responsabilizando-se a raça negra ou ameríndia ou mesmo a 
8 "A precoce voluptuosidade, a fome de mulher que aos treze ou quatorze anos faz de todo o brasileiro um dom-juan não vem do contágio ou do sangue da 'raça inferior', mas do sistema econômico e social da nossa formação; e um pouco talvez do clima" (Freyre, 1933, p. 320).

9 A argumentação de Freyre é contra Joaquim Nabuco, que afirmava que a sífilis era uma influência do contato do Brasil com a África. portuguesa, cada uma das quais, pura ou sem cruzamento, está cansada de produzir exemplares admiráveis de beleza e de robustez física, pelo "feio" e pelo "bisonho" das nossas populações mestiças mais afetadas de sífilis ou roídas de verminose.

A desvinculação da sifilização da miscigenação é um outro aspecto importante para esse trabalho. Como afirmamos, durante o século passado e início deste, a sífilis foi vista como um dos principais fatores de degeneração da raça. Além de ser considerada uma doença hereditária por muitos médicos, chegou-se a acreditar que a corrupção física por ela causada podia ser transmitida a gerações subseqüentes, como caracteres adquiridos. Além disso, a despeito da inexistência de estatísticas, para muitos médicos a sífilis tinha enorme incidência entre a nossa população. Tal fato se explica, em parte, pela inexistência de um diagnóstico preciso da doença que expurgasse de sua caracterização um conjunto de sintomas que se julgava adstrito a ela. Segundo Carrara (1995, p. 167), o que mais determinava esse diagnóstico não era a fundamentação epidemiológica, mas a noção de que o brasileiro era afeito a excessos sexuais.

Parece não haver dúvida quanto ao fato de a percepção de o Brasil ser um país de sifilíticos ser caudatária da idéia mais geral de serem os brasileiros particularmente excessivos sexualmente. ... Sabese que tal crença remonta ao início da empresa colonial, tendo sido retomada fortemente a partir do final do século XIX, no âmbito do esforço empreendido pelas elites intelectuais brasileiras no sentido de compreender "cientificamente" a nossa formação social e suas mazelas.

Essa noção, em muito herdada da climatologia médica do século passado, persistiria na primeira metade deste século através de autores como Nina Rodrigues e Paulo Prado. Até mesmo Freyre comungava até certo ponto com ela, afirmando a sensualidade do brasileiro. No entanto, ele não descura de seu referencial analítico. A seu ver, a depravação sexual que fez parte do período colonial não se relacionava a motivos raciais, mas ao tipo de organização social patriarcal escravista que, por si, era um elemento estimulador da luxúria. ${ }^{8}$ É esse referencial que o permite contradizer os que postulavam a culpa dos índios ou dos negros no processo de sifilização. ${ }^{9}$ Os índios foram, na verdade, sifilizados pelo colonizador, impelido à miscigenação pela falta de mulheres européias; já os negros seriam vítimas da sanha procriadora de seus senhores, ávidos por novas crias mestiças para transformar em moleques e, transformados pelo poder de possuir homens, em sádicos, prontos a submeter também as escravas a suas vontades de macho.

Freyre também salienta que a persistência da doença em nosso país não pode ser atribuída a uma pretensa lubricidade da raça 
10 Segundo Freyre (1933, p. 316), "Passa por ser defeito da raça africana, comunicado ao brasileiro, $\mathrm{O}$ erotismo, a luxúria e a depravação sexual. Mas o que se tem apurado entre os povos negros da África, como entre os primitivos em geral, é maior moderação do apetite sexual que entre os europeus. $\mathrm{E}$ uma sexualidade, a dos negros africanos, que para excitar-se necessita de estímulos picantes. Danças afrodisíacas. Culto fálico. Orgias. Enquanto que no civilizado o apetite sexual de ordinário se excita sem grandes provocações ... demonstrando a necessidade entre eles de excitação artificial..."

11 Sua adesão ao neolamarckismo é explicitada entre as páginas 292 e 294 de Casa-grande e senzala. negra. Asseverando que os europeus apresentam maior apetite sexual que os africanos, ${ }^{10}$ ele conclui que, mesmo quando os negros tiveram participação ativa na vida sexual extrafamiliar dos brancos, não devem ser vistos como raça, mas como fruto de um sistema escravista por si degradante da moral.

A contaminação sifilítica se ligaria, ainda, a outros aspectos da sociedade escravista. Segundo Freyre, a utilização de escravas como amas-de-leite permitia a sua contaminação pelas crianças sifilíticas. Além disso, ele aponta que nas casas-grandes e senzalas a doença era vista com tanta naturalidade que as marcas que deixava nos corpos dos filhos dos senhores de engenho passaram a ser encaradas como símbolo de masculinidade.

Os aspectos analisados por Freyre fazem parte do conjunto de elementos destacados por Carrara (1997, p. 392) como centrais no discurso médico sobre a sífilis entre as décadas de 1920 e 1940. A origem geográfica da doença, sua forma de disseminação no Brasil, comparativamente a outros países, e a singularidade de seus sintomas entre os brasileiros seriam as principais questões discutidas pelos médicos neste período. A seu ver, os sifilógrafos foram os principais agentes no deslocamento da questão da sífilis da esfera da de degeneração da raça para o campo da patologia social. Tal deslocamento "abriu a possibilidade de se pensar uma redenção mais rápida e segura para o país". Para Carrara (idem, p. 404), Freyre seria caudatário dessa nova forma de ver a doença empreendida pelos sifilógrafos, e Casa-grande e senzala, um significativo exemplo do forte impacto da reflexão médica sobre a doença no pensamento social brasileiro.

Para esse trabalho, é importante ressaltar que a nova forma de ver o problema da sífilis em nosso país não foi um acontecimento isolado, ela se inseriu no contexto mais geral de mobilização pela saúde observado na primeira seção e, como dissemos, teve grande repercussão no pensamento social do período. Cabe agora observar como a questão da saúde se vinculou à da raça, e como estes dois aspectos estão imbricados com nosso autor.

\section{Da higiene à eugenia}

Freyre reserva algumas páginas de Casa-grande e senzala para afirmar sua filiação ao neolamarckismo. ${ }^{11}$ Essa corrente do pensamento evolucionista, eclipsada a partir do final do século XIX pela teoria darwinista, que postulava a seleção natural e a lenta evolução dos seres ao acaso, se manteve forte entre os cientistas e intelectuais franceses. Apoiava-se na premissa de que os organismos teriam a capacidade de incorporar caracteres adquiridos a seu patrimônio individual e transmiti-los a seus descendentes. Em virtude da grande influência francesa na formação 
12 Em relação à forma como Freyre utiliza os conceitos de raça e cultura, ver Araújo (1994, primeiro capítulo).

${ }^{13}$ Segundo Stepan (1991, 1985), essa teoria teve um papel relevante na história da eugenia brasileira: foi decisiva na incorporação dos aspectos positivos da miscigenação pelos nossos médicos e cientistas sociais e proporcionou a incorporação das questões de saúde e saneamento como essenciais à melhoria da raça -

especificidade da concepção de eugenia brasileira frente à dos países anglo-saxões.

"Structurally and scientifically, too, in the 1920 the neo lamarckian outlook in eugenics was broadly congruent with the sanitation sciences, which had only recently established themselves at the center of programs of improvement. These sciences had significant ideological meanings on which eugenics could also draw and which worked to pull eugenics at first in a sanitation oriented reformist direction." cultural brasileira - em especial na área das ciências biomédicas —, o neolamarckismo deu o tom a diversos estudos médicos, sociológicos e antropológicos durante a primeira metade deste século (Stepan, 1995). Para Freyre, ele foi uma excelente ferramenta teórica para explicar a peculiaridade do caráter brasileiro pelas características herdadas dos povos que aqui aportaram a partir do descobrimento, acrescidas das influências do meio físico, dos aspectos sócio-econômicos que moldavam nossa estrutura social e da própria cultura nacional em formação. Sua filiação ao neolamarckismo the permitiu, também, operar com os conceitos de raça e cultura para sublinhar a viabilidade do Brasil miscigenado. ${ }^{12}$

Em seus trabalhos sobre eugenia, Stepan ressalta que a grande aceitação da teoria neolamarckista entre os médicos e intelectuais brasileiros foi importante na configuração peculiar que a eugenia teve em nossa terra. ${ }^{13} \mathrm{O}$ lamarckismo já havia servido de ponto de apoio às idéias de degeneração racial, de grande alcance no pensamento médico brasileiro do século passado. Partindo de uma concepção monogenista, essa teoria postulava que a pretensa inferioridade de determinadas raças era produto de circunstâncias ambientais e sociais que teriam o poder de corromper os sistemas vitais, sendo transmitidas hereditariamente. Nas primeiras duas décadas deste século, o neolamarckismo serviria de alavanca para uma concepção oposta: a possibilidade de regeneração do país pela melhoria da raça. Regeneração essa vinculada, de pronto, pelos nossos médicos e intelectuais à questão da saúde. Se as doenças causavam danos aos indivíduos, que, por transmissão hereditária, resultavam na depauperação de sua prole, a subtração dessas mazelas representava seguramente a garantia de melhorias eugênicas.

Pelo que foi dito até o momento, fica a tentação de elaborarmos uma equação simples entre neolamarckismo e eugenia, resultando no movimento pelo saneamento como redenção do país, influência que julgamos fundamental no trabalho de Freyre. Nesse caso, estaríamos incorrendo num equívoco. A trajetória de dois importantes atores do movimento pela eugenia demonstra esse problema. O médico neolamarckista Renato Kell, secretário da Sociedade de Eugenia de São Paulo, e um dos principais propagandistas da eugenia durante a década de 1920, era contrário à aproximação da eugenia da higiene, e acabou se identificando com idéias racistas na década de 1930 (Stepan, 1985, p. 368). O já citado antropólogo Roquette-Pinto era adepto da teoria mendeliana, no entanto, foi um dos primeiros a postular o valor positivo da miscigenação. A seu ver, a eugenia deveria se relacionar a ações educativas e higiênicas. Como vimos, suas idéias sobre raça são várias vezes citadas no trabalho de Freyre e incorporadas a algumas de suas conclusões. 
${ }^{14}$ Ver, a esse

respeito, a nota 3 da introdução à primeira edição de Casa-grande e senzala, onde Freyre cita as pesquisas antropométricas de Boas.
A filiação neolamarckista de Freyre é um aspecto marcante. Isso fica claro em algumas passagens de sua obra, como, por exemplo, quando postula que a inferioridade física dos sertanejos se deve à subnutrição de seus antepassados, sob o regime escravista. No entanto, esta constatação deve ser matizada, à medida que seu referencial em antropologia cultural também concorria para esta forma de pensar. ${ }^{14}$

O que se mostra mais relevante é que Freyre atribuiu grande importância a aspectos que eram centrais aos eugenistas de sua época. Além do problema da sífilis, isto pode ser observado em várias outras passagens de Casa-grande esenzala, como as que tratam do alcoolismo, dos efeitos dos casamentos co-sanguíneos, e da grande mortalidade infantil, em virtude da ignorância de medidas básicas de higiene. De forma semelhante ao que vimos em relação à saúde, ele utiliza os argumentos eugênicos para desfazer a lógica racial de algumas explicações sobre o país. Por isso, a sífilis torna-se relevante em seu trabalho; ao retomar as idéias dos sifilógrafos que postulavam que a doença não era fruto da miscigenação racial, e sim uma patologia social, ele reforçava o argumento principal de seu ensaio.

\section{Conclusão}

Procuramos, neste artigo, observar como as questões de saúde e doença foram vistas por Freyre em Casa-grande e senzala. Acreditamos ter demonstrado que a especificidade dessa apresentação incorre no fato de ela se vincular à questão da raça e da miscigenação, procurando anular as análises sociais de cunho racista. Isso não quer dizer que somente os problemas de saúde identificados com essas questões apareçam nesta obra. Em vários momentos do livro, deparamos com referências ao tema apresentadas de forma mais sucinta e menos analítica. Outro aspecto que colocamos em relevo diz respeito à influência do movimento pelo saneamento, ocorrido no final da década de 1910, na obra de Freyre. No entanto, é imperioso que apresentemos a outra face dessa moeda. Se esta influência foi importante no trabalho de Freyre, sua obra deixaria marcas indeléveis nas análises sobre raça e miscigenação. Como afirma Skidmore (1976, p. 210),

Casa-grande e senzala virou de cabeça para baixo a afirmação de ter a miscigenação causado dano irreparável. O pot-pourri étnico do Brasil, dizia Gilberto Freyre, era, ao contrário, uma vantagem imensa. Mostrou como as pesquisas de nutrição, antropologia, medicina, psicologia, sociologia e agronomia tinham tornado obsoletas as teorias raciais e apontado novos vilãos - a dieta insuficiente, a indumentária pouco prática, a doença muitas vezes nem diagnosticada nem tratada (especialmente a sífilis). ... Assim, Gilberto Freyre conseguiu fazer para um vasto público a consciência que o país começava a ter das dimensões raciais de seu passado. 


\section{REFERÊNCIAS BIBLIOGRÁFICAS}

Araújo, R. Benzaquen 1994

Benchimol, Jaime e

Teixeira, Luiz A. 1993

Benchimol, Jaime (org.) 1990

Carrara, Sérgio L. fev. 1997

Carrara, Sérgio L. 1995

Cunha, Euclides da 1966

Freyre, Gilberto 1996

Freyre, Gilberto 1995

Freyre, Gilberto 1989

Hochman, Gilberto e Lima, Nísia Trindade 1996

Labra, Maria Eliana 1985

Maio, Marcos Chor jul. 1994

Roquette-Pinto, Edgard 1929

Skidmore, Thomas E. 1976

Stepan, Nancy Leys 1991

Stepan, Nancy Leys set.-dez. 1985
Guerra e paz: Casa-grande e senzala e a obra de Gilberto Freyre nos anos 30. Rio de Janeiro, Editora 34.

Cobras, lagartos e outros bichos: uma história comparada dos institutos Oswaldo Cruz e Butantan. Rio de Janeiro, Fiocruz/UFRJ.

Manguinhos do sonho à vida: a ciência na Belle Époque. Rio de Janeiro, Fiocruz.

'A geopolítica simbólica da sífilis: um ensaio de antropologia histórica'.

História, Ciências, Saúde - Manguinhos, vol. III, $\mathrm{n}^{0} 3$.

'O tributo a Vênus: a luta contra a sífilis no Brasil, da passagem do século aos anos 40'. Tese de doutoramento, Rio de Janeiro, PPGAS/Museu Nacional/UFRJ.

Os sertôes. Em Euclides da Cunha: obra completa.

Rio de Janeiro, Companhia José Aguilar Editora. Biblioteca Luso-Brasileira.

Sobrados e mucambos: decadência do patriarcado rural e desenvolvimento do urbano. $9^{a}$ ed., Rio de Janeiro, Record.

Casa-grande e senzala: formação da família brasileira sob o regime da economia patriarcal $30^{\mathrm{a}}$ ed., Rio de Janeiro, Record.

Nordeste: aspectos da influência da cana sobre a vida e a paisagem do Nordeste do Brasil. 6a ed., Rio de Janeiro, Record.

'Condenado pela raça, absolvido pela medicina: o Brasil redescoberto pelo movimento sanitarista da primeira república'. Em Marcos Chor Maio e Ricardo Ventura Santos (orgs.), Raça, ciência e sociedade. Rio de Janeiro, Editora Fiocruz/CCBB.

'O movimento sanitarista nos anos 20: da conexão internacional à especificidade da saúde pública no Brasil'. Dissertação de mestrado, Rio de Janeiro, Ebap/FGV.

'Raça e cultura: reflexões sobre o estoque semita de Gilberto Freyre'. III Congresso Afro-Luso-Brasileiro de Ciências Sociais. Lisboa.

'Notas sobre os tipos antropológicos do Brasil'. Primeiro Congresso Brasileiro de Eugenia. s. ed.

Preto no branco: raça e nacionalidade no pensamento brasileiro. Rio de Janeiro, Paz e Terra.

The hour of eugenics, race, gender, and nation in Latin America. Londres, Cornnell University Press.

'Eugenésia, genética y salud pública: El movimiento eugenésico brasileño y mundial'. Quipu, Revista Latinoamericana de Historia de las Ciencias y la Tecnología, vol. 2, n² 3, México. 